\title{
AN ESTIMATE FROM PEDIGREE DATA OF THE GENE FREQUENCY FOR COLOUR BLINDNESS
}

\author{
BY \\ GEORGE KNOX* \\ From the Department of Social Medicine, University of Birmingham
}

There are several possible approaches to the measurement of the population gene-frequency for colour blindness, and each approach has its particular advantages and disadvantages.

The first is the direct approach of a population survey and especially, since the disease is commoner in males, a measurement of its incidence in men. In the event of full penetrance and ascertainment of the $\dot{X} Y$ genotype, the mathematical treatment is commendably simple, for the incidence in men is numerically equal to the gene frequency. The weakness of the method, however, is its dependence upon the presumption of full penetrance and this difficulty is manifest in the varying estimates yielded by different methods at different times. Bell (1933) quotes a survey in 1892 which yielded an estimate of $2 \cdot 18$ per cent. male incidence; Gates (1946) quotes another early survey of 14,846 persons where the male incidence was $4 \cdot 16$ per cent., and other more recent surveys give estimates in European populations of 6. 63 per cent. (Grieve, 1946), 7.49 per cent. (Vernon and Straker, 1943), 7.95 per cent. (von Planta, 1928) 8 per cent. (Wright), 8.07 per cent. (Waaler, 1927) 9. 7 per cent. (Wieland, 1933), and 10.07 per cent. (Schiötz, 1922). Detection of colour blindness by Ishihara charts is no doubt responsible for recent estimates being higher than earlier ones. But even allowing for this and for the fact that there seem to be geographical variations in the incidence of colour blindness (see Vernon and Straker, 1943), the variations among the different estimates of incidence are sufficient to cause some doubt about the validity of direct conversion of the male incidence to a genefrequency estimate. Nor indeed would a higher degree of consistency necessarily validate such a conversion; used alone the method does not provide any objective means of assessing its own propensity to overor under-estimate.

The second approach depends upon the sex ratio of the disease. While the male incidence of a sexlinked disease is proportional to the gene frequency $(g)$, the female incidence is proportional to its square $\left(g^{2}\right)$ (Knox, 1958; Dahlberg, 1947), and provided

\footnotetext{
- Medical Research Council Clinical Research Fellow.
}

that the penetrances in the two sexes are equal, though not necessarily complete, the ratio Female affected/Male affected in a population provides an estimate of $g$. Since the premise upon which this is based is different from the premise of the first method (full penetrance in males) it provides a very useful check. Its disadvantage arises because sex-linked disorders are relatively rare in females and even enormous population surveys yield quite small numbers.

Schiötz (1922) reported an incidence of 10.07 per cent. in 2,005 males and 0.91 per cent. in 2,200 females. The $F / M$ ratio is 0.9 , a reasonably close check upon an estimate of $g$ derived from the incidence in males. The 95 per cent. limits for the $F / M$ ratio are $0.052-0.162$, wide enough to be compatible with the incidence in males but also wide enough to deprive the estimate of precision.

Waaler (1927) reported an incidence of 8.07 per cent. in 9,047 males and 0.44 per cent. in 9,072 females. Here the $F / M$ ratio is only 0.055 , considerably less than the gene-frequency estimate based upon the male incidence. Again, however, the 95 per cent. limits of the ratio are wide, 0.039-0.075, and it is doubtful if the difference between the results of the two methods could be considered statistically significant. But the same remarks apply here as to the data given by Schiötz, the sex ratio seems only to confirm the accuracy of direct estimates in a very general way and in a survey of manageable size can scarcely hope to compete in precision.

A third example of the difficulties of this approach is found in the data of Kilborn and Beh (1934), who found an incidence of 6.5 per cent. in 2,279 male Chinese and 1.7 per cent. in 1,132 females. The sex ratio gives a gene-frequency estimate of $0 \cdot 26$, an inconsistency in the opposite direction to Waaler's and much of it reasonably attributable once more to the small numbers.

A similar inconsistency of greater extent is found in the data of Schmidt (1945), who is reported as finding an incidence of 7 per cent. in males and 4 per cent. in females.

These checks upon direct estimates of the gene frequency for colour blindness generally confirm 
that it is between about 0.05 and 0.10 in most European populations, but additional data would clearly be welcome. The accurate estimation of the population sex ratio requires large investigations, and I wondered whether legitimate use could be made of existing pedigrees of families with the disorder.

\section{METHOD}

Since the collection of such records is not related to any definable population, a suitable method must depend upon the relative numbers of males and females, and, since selection for publication is based in part upon the number of affected individuals in a family and this in turn is related to the sex ratio, the method should clearly make allowances for such selection. While a precise correction is probably too much to hope for, it seemed possible that one of the algebraic relationships derived from a recent consideration of sex-linked inheritance (Knox, 1958) might supply a sufficiently accurate method. It depends upon the expected frequencies of pairs of affected sibs of the types MM, MF, and FF in the respective relative proportions $1: 2 g: g$, where $g$ is the frequency of a sex-linked recessive gene. An estimate based upon a count of such pairs selects families in much the same way as publication might be expected to do, for it ignores families with less than two affected sibs and it takes greater note of larger sibships, taking $n(n-1) / 2$ units of information for a family with $n$ affected sibs (see below). We might therefore expect it to be reasonably robust and relatively resistant to the kind of bias introduced by publication.

The ratios $1: 2 g: g$ were derived originally from the product of the sex ratios of the first of a pair and the expected sex ratio in the next (Knox, 1958). The relationship applies to the sum of all possible pairs when more than two individuals are affected in a sibship, that is, three pairs for three affected, six pairs for four affected, ten pairs for five affected and in general $n(n-1) / 2$ for $n$ affected. In order to improve confidence in the contention that all pairs should be counted, an alternative derivation of expected pair frequencies in sibships of size 2 and 3 is presented in the next two panels. These frequencies are based upon successive multiplication of population parental mating-type frequencies, the binomial probabilities of different sex constitutions of the families, and, in each case, the expected genotype frequency combinations. It can be seen that the ratios $1: 2 g: g$ are derived by the addition of the probabilities of all possible pairs of the appropriate types.

It follows from this that the ratio (MF + FF)/MM is $3 g$, and that an estimator of $g$ which uses all the information is:

$$
\frac{1}{3} \cdot \frac{\mathrm{MF}+\mathrm{FF}}{\mathrm{MM}} .
$$

SiBSHIP SIZE 2

METHOD

\begin{tabular}{|c|c|c|c|c|c|c|c|c|c|c|}
\hline \multirow{3}{*}{$\begin{array}{l}\text { Parental Mating } \\
\text { Types and } \\
\text { Frequencies }\end{array}$} & \multicolumn{10}{|c|}{ Constitution of Family and Frequencies } \\
\hline & \multicolumn{3}{|c|}{$1 / 4$} & \multicolumn{4}{|c|}{$1 / 2$} & \multicolumn{3}{|c|}{$1 / 4$} \\
\hline & $M M$ & $M \mathbf{M}$ & MM & $M F$ & $M F$ & $\mathbf{M} F$ & MF & $F F$ & $F F$ & FF \\
\hline $\begin{array}{lll}\dot{X} \dot{X} & & \dot{X} Y \\
& g^{3} & \end{array}$ & 1 & 0 & 0 & 1 & 0 & 0 & 0 & 1 & 0 & 0 \\
\hline$X \dot{X} \underset{2 g^{2}(1-g)}{\dot{X} Y}$ & $\frac{1}{4}$ & $\frac{1}{2}$ & $\frac{1}{4}$ & $\frac{1}{4}$ & 1 & $\mathbf{0}$ & $\frac{1}{4}$ & 1 & $\frac{1}{2}$ & $\frac{1}{4}$ \\
\hline$X X \underset{g(1-g)^{2}}{ } \dot{X} Y$ & 0 & 0 & 1 & 0 & 0 & 0 & 1 & 0 & 0 & 1 \\
\hline$\dot{X X} \underset{g^{2}(1-g)}{X Y}$ & 1 & 0 & $\mathbf{0}$ & 0 & 0 & 1 & $\mathbf{0}$ & $\mathbf{0}$ & 0 & 1 \\
\hline$X \dot{X} \underset{2 g(1-g)^{2}}{X Y}$ & $\frac{1}{4}$ & $\frac{1}{2}$ & $\frac{1}{4}$ & 0 & $\frac{1}{2}$ & 0 & $\frac{1}{2}$ & 0 & 0 & 1 \\
\hline$X X \underset{(1-g)^{3}}{X Y}$ & 0 & 0 & 1 & 0 & 0 & 0 & 1 & 0 & 0 & 1 \\
\hline
\end{tabular}

The cells contain probabilities of 2, 1, 0 affected children for each parental mating type and sex constitution of the family. $M, F$ indicate affected individuals, $\dot{X} \dot{X}$ or $\mathbf{X Y}$, and $\mathbf{M}, F$ indicate unaffected individuals. 
SibShIP Size 2

\section{SUMMARY OF SIB-PAIRS}

\begin{tabular}{|c|c|}
\hline $\begin{array}{l}M M \\
M F \\
F F\end{array}$ & $\begin{array}{l}g(1+g) / 8 \\
g^{2}(1+g) / 4 \\
g^{2}(1+g) / 8\end{array}$ \\
\hline $\begin{array}{l}M \mathrm{M} \\
M \mathrm{~F}\end{array}$ & $\begin{array}{l}g(1-g) / 4 \\
g(1-g)(2+g) / 4\end{array}$ \\
\hline $\begin{array}{l}F \mathrm{~F} \\
F \mathrm{M}\end{array}$ & $\begin{array}{l}g^{2}(1-g) / 4 \\
g^{2}(1-g) / 4\end{array}$ \\
\hline $\begin{array}{l}\text { MM } \\
\text { MF } \\
\text { FF }\end{array}$ & $\begin{array}{l}(1-g)(2-g) / 8 \\
(1-g)\left(2-g^{2}\right) / 4 \\
(1-g)\left(2+2 g-g^{2}\right) / 8\end{array}$ \\
\hline
\end{tabular}

The ratios $M M: M F: F F$ are $1: 2 g: g$.

The ratio $F: M$ is $g$.

\section{Data AND ANalysis}

The data used for the present estimate are the pedigrees for "Congenital Colour Blindness" published by Bell (1933). There are 185 such pedigrees (Nos. 406 to 590 inclusive). One of these (No. 431) is excluded because it is so atypical and is obviously not a sex-linked recessive transmission. Of the remaining 184 pedigrees, 139 contain at least one affected pair of sibs.

The total numbers of affected sib-pairs, counting all recorded generations and all possible paircombinations are as follows:

$\begin{array}{ccc}\text { MM } & \text { MF } & \text { FF } \\ 489 & 71 & 31\end{array}$

The expected 2:1 MM:FF ratio is very closely realized (see also Csik and Mather, 1937), and the distribution is very different from a binomial distribution.

SIBSHIP SIZE 3

SUMMARY OF SIBSHIPS AND OF AFFECTED PAIRS

\begin{tabular}{|c|c|c|c|c|c|}
\hline \multirow{2}{*}{\multicolumn{3}{|c|}{ Sipships }} & \multicolumn{3}{|c|}{ Possible Pairs } \\
\hline & & & \multirow{2}{*}{$\begin{array}{c}M M \\
3 g(1+3 g) / 32 \\
3 g^{2}(1+3 g) / 32 \\
-\end{array}$} & \multirow{2}{*}{$\begin{array}{c}M F \\
\begin{array}{c}6 g^{2}(1+3 g) / 32 \\
6 g^{2}(1+3 g) / 32 \\
-\end{array}\end{array}$} & \multirow{2}{*}{$\begin{array}{c}F F \\
- \\
3 g^{2}(1+3 g) / 32 \\
3 g^{2}(1+3 g) / 32\end{array}$} \\
\hline $\begin{array}{l}M M M \\
M M F \\
M F F \\
F F F\end{array}$ & $\begin{array}{l}g(1+3 g) / 32 \\
3 g^{2}(1+3 g) / 32 \\
3 g^{2}(1+3 g) / 32 \\
g^{2}(1+3 g) / 32\end{array}$ & $\begin{array}{l}\cdots \\
\cdots \\
\cdots\end{array}$ & & & \\
\hline $\begin{array}{l}M M M \\
M M F\end{array}$ & $\begin{array}{l}3 g(1-g) / 32 \\
3 g(1-g)(2+3 g\end{array}$ & $\ddot{.}$ & $\begin{array}{l}3 g(1-g) / 32 \\
3 g(1-g)(2+3 g) / 32\end{array}$ & $\overline{-}$ & - \\
\hline $\begin{array}{l}F F \mathrm{~F} \\
F F \mathrm{M}\end{array}$ & $\begin{array}{l}3 g^{2}(1-g) / 32 \\
3 g^{2}(1-g) / 32\end{array}$ & .. & - & $=$ & $\begin{array}{l}3 g^{2}(1-g) / 32 \\
3 g^{2}(1-g) / 32\end{array}$ \\
\hline $\begin{array}{l}M F M \\
M F F\end{array}$ & $\begin{array}{l}3 g^{2}(1-g) / 16 \\
3 g^{2}(1-g) / 16\end{array}$ & $\because$ & - & $\begin{array}{l}3 g^{2}(1-g) / 16 \\
3 g^{2}(1-g) / 16\end{array}$ & 二 \\
\hline $\begin{array}{l}\text { MMM } \\
M \mathrm{MF} \\
M \mathrm{FF}\end{array}$ & $\begin{array}{l}3 g(1-g) / 32 \\
3 g(1-g)(2-g) \\
3 g(1-g)(4+g)\end{array}$ & & E & E & E \\
\hline $\begin{array}{l}F F F \\
F F M \\
F M M\end{array}$ & $\begin{array}{l}3 g^{2}(1-g) / 32 \\
3 g^{2}(1-g) / 16 \\
3 g^{2}(1-g) / 32\end{array}$ & & E & E & z \\
\hline $\begin{array}{l}\text { MMM } \\
\text { MMF } \\
\text { MFF } \\
\text { FFF }\end{array}$ & $\begin{array}{l}(1-g)(4-3 g) / \\
3(1-g)(4-2 g \\
3(1-g)\left(4-3 g^{2}\right. \\
(1-g)(4+4 g\end{array}$ & & $\begin{array}{l}\bar{z} \\
\overline{-}\end{array}$ & $\bar{z}$ & $\begin{array}{l}- \\
-\end{array}$ \\
\hline \multirow{2}{*}{\multicolumn{3}{|c|}{$1 \cdot 0$}} & $3 g(1+g) / 8$ & $3 g^{2}(1+g) / 4$ & $3 g^{2}(1+g) / 8$ \\
\hline & & & 1 & $2 g$ & $g$ \\
\hline
\end{tabular}


Numbers of affected males and females in the 184 families are 845 and 93, some individuals being counted several times in the pair-combinations and others not at all.

The sex ratio is therefore $0 \cdot 11$, but reasons have been given for supposing that this is not a legitimate estimate of $g$ in the present circumstances. On the other hand the method based on the MM : MF : FF ratios and proposed above as a legitimate one gives:

$$
g=\frac{1}{3} \cdot \frac{\mathrm{MF}+\mathrm{FF}}{\mathrm{MM}}=\frac{1}{3} \cdot \frac{102}{489}=0.070 \text {. }
$$

The 95 per cent. limits for this estimate (i.e. based on the ratio $102: 489$ ) are $0.056-0.086$.

\section{ConClusions}

The precision of this result is higher than for the estimates based upon the sex ratio in populations, and in magnitude it corresponds closely with most of the estimates based upon male incidence as measured by Ishihara testing. This close correspondence is noteworthy from several points of view.

First, it is an endorsement of Ishihara testing as an accurate means of detecting colour blindness. Secondly, it confirms the validity of the concept of a sex-linked recessive gene as the main determinant of the defect. Alternatively, since the present result is manifestly sensible in relation to others, it can be regarded as an endorsement of the method used.

\section{SUMMARY}

Gene-frequency estimates for colour blindness have been obtained by two main methods, the first depending upon the incidence of the defect in males, the other upon the sex ratio. The methods depend on different premises and provide a useful mutual check but the second method can give precise results only in enormous surveys. A new method is suggested based upon published pedigree data. It is found to give a relatively precise result and the estimate of 0.07 corresponds closely with those of direct methods.

\section{REFERENCES}

Bell, J (1933). "Treasury of Human Inheritance", vol. 2. University Press, Cambridge.

Csik, J., and Mathur, K. (1937). Ann. Eugen. (Lond.), 8, 126.

Dahlberg, G. (1947). "Mathematical Methods for Population Genetics". Karger, Basel.

Gates, R. R. (1946). "Human Genetics", vol. 1. Macmillan, New York.

Grieve, H. (1946). Nature (Lond.), 157, 376.

Kilborn, L. G., and Beh, Y. T. (1934). Science, 79, 34.

Knox, G. (1958). Brit. J. prev. soc. Med., 12, 183

Planta, P. von (1928). v. Graefes Arch. Ophthal., 120, 253.

Schiötz, I. (1922). Klin. Mbl. Augenheilk., 68, 498.

Schmidt, I. (1945). Unpublished data.

Vernon, P. E., and Straker, A. (1943). Nature (Lond.), 152, 690.

Waaler, G. H. M. (1927). Z. indukt. Abstamm. u. VerebLehre, 45, 279 (cited by Gates, 1946, p. 154).

Wieland, M. (1933). v. Graefes Arch. Ophthal., 130, 441.

Wright, W. D. (1944). "The Measurement of Colour", p. 52. Hilger.

London. 